\title{
Cross-insitutional standardization of imaging protocols - A pilot study within the scope of the Comprehensive Cancer Center Lower Saxony
}

\section{Standortübergreifende Standardisierung von Untersuchungsprotokollen - eine Pilotstudie im Rahmen des Comprehensive Cancer Centers Niedersachsen}

Authors

Inka Römermann¹, Omar Al-Bourini², Ali Seif Amir Hosseini², Jan B. Hinrichs', Frank K. Wacker ${ }^{1}$, Joachim Lotz², Kristina I. Ringe ${ }^{1}$

Affiliations

1 Department of Diagnostic and Interventional Radiology, Hannover Medical School, Hannover, Germany

2 Institute for Diagnostic and Interventional Radiology, University Medical Center Göttingen, Göttingen, Germany

Key words

liver, pancreas, standard operating procedures, SOP, CT, MRI

received 14.04 .2020

accepted 03.08.2020

published online 03.09 .2020

Bibliography

Fortschr Röntgenstr 2021; 193: 410-416

DOI $10.1055 / \mathrm{a}-1238-2925$

ISSN 1438-9029

(c) 2020. Thieme. All rights reserved.

Georg Thieme Verlag KG, Rüdigerstraße 14,

70469 Stuttgart, Germany

Correspondence

Prof. Dr. Kristina Imeen Ringe

Diagnostische Radiologie, Medizinische Hochschule

Hannover, Carl-Neuberg-Straße 1, 30625 Hannover, Germany

Tel.: ++49/5 11/5323424

Fax: $++49 / 511 / 5323885$

ringe.kristina@mh-hannover.de

\section{ABSTRACT}

Purpose Cross-institutional establishment of standardized protocols for CT and MR imaging of primary liver and pancreas tumors in an oncological center.

Materials and Methods This prospective dual-institution study was approved by the local IRBs. Minimum requirements (phases, sequences, slice thickness) for imaging of primary liver and pancreas tumors were defined and implemented at both sites. Between 06/19 and 08/19 in-house examinations were evaluated in terms of compliance with defined protocols and image quality. In addition, extramural examinations that were demonstrated at interdisciplinary tumor board meetings in the same study period were reviewed. Results were analyzed by means of descriptive statistics, and differences between centers, modalities and organs assessed (Fisher-exact Test, $\mathrm{p}<0.05$ deemed significant).

Results 480 data sets (397 internal, 83 extramural) were included in this study and analyzed. Overall protocol compliance for in-house examinations was $93.5 \%$ (371/397 datasets), without statistical significant difference between the two institutions $(p=0.0615)$. External studies met minimum requirements in $48.2 \%$ (40/83 datasets). Regarding in-house imaging, significant differences were observed between CT of the liver and the pancreas $(p<0.05)$ and between $C T$ and MRI of the pancreas $(p<0.05)$.

Conclusion As demonstrated in this pilot project, cross-institutional establishment of standardized imaging protocols is feasible with a compliance rate of more than $90 \%$. Standardized imaging protocols may serve as a quality indicator in oncological imaging, and over time, improve cross-institutional patient care.

Key points:

- Cross-institutional establishment of standardized imaging protocols is feasible with high compliance.

- Standards may serve as a quality indicator in oncological imaging.

- In perspective, cross-institutional patient care may be improved.

\section{Citation Format}

- Römermann I, Al-Bourini O, Seif Amir Hosseini A et al. Cross-insitutional standardization of imaging protocols A pilot study within the scope of the Comprehensive Cancer Center Lower Saxony. Fortschr Röntgenstr 2021; 193: 410-416

\section{ZUSAMMENFASSUNG}

Ziel Standortübergreifende Etablierung von standardisierten Untersuchungsprotokollen für die Bildgebung von primären Leber- und Pankreastumoren in der CT und MRT in einem onkologischen Zentrum. 
Material und Methoden Diese biinstitutionelle prospektive Beobachtungsstudie wurde durch die Ethikkommission der beteiligten Institute genehmigt. Minimalanforderungen (Phasen, Sequenzen, Schichtdicke) für die CT- und MRT-Bildgebung von primären Leber- und Pankreastumoren wurden definiert und in den Instituten implementiert. Im Zeitraum von 06/19 bis 08/19 wurden an beiden Standorten die institutionsinternen Datensätze von Patienten mit entsprechender klinischer Fragestellung im Hinblick auf Einhaltung definierter Protokolle und Bildqualität ausgewertet. Zusätzlich erfolgte die Begutachtung von externen Untersuchungen, welche im selben Zeitraum im Rahmen interdisziplinärer Tumorkonferenzen demonstriert wurden. Die Ergebnisse wurden mittels deskriptiver Statistik ausgewertet und Unterschiede zwischen den Instituten, Modalitäten und Organen mittels Fisher-exakt-Test erfasst ( $p<0,05$ signifikant).

Ergebnisse Insgesamt wurden 480 Datensätze (397 interne, 83 externe) in die Studie eingeschlossen und ausgewertet.
Die Einhaltung der definierten Protokolle für die internen Untersuchungen lag übergreifend an beiden Instituten bei 93,5\% (371/397 Datensätze), ohne signifikanten Unterschied zwischen den beiden Instituten $(p=0,0615)$. Die externen Untersuchungen erfüllten in 48,2 \% (40/83 Datensätze) die Minimalanforderungen. Zentrumsintern waren signifikante Unterschiede zwischen CT-Untersuchungen der Leber und des Pankreas nachweisbar $(p<0,05)$ sowie zwischen Untersuchungen des Pankreas in der CT und MRT $(p<0,05)$.

Schlussfolgerung Eine institutionsübergreifende Standardisierung von Untersuchungsprotokollen ist möglich, wie in diesem Pilotprojekt gezeigt werden konnte, mit der Einhaltung definierter Protokolle in über $90 \%$. Untersuchungsstandards können als Qualitätsindikator für die onkologische Bildgebung dienen und perspektivisch die zentrumsübergreifende Patientenversorgung verbessern.

\section{Introduction}

An increasing incidence of cancer can be seen throughout Germany. According to statistics from the German Center for Cancer Registry Data, a total of 426800 new cases were recorded in 2006, and in 2016, 492090 incidences [1], accompanied by correspondingly increasing demands in clinical patient care. In order to respond to this, there are now, among other things, supra-regional initiatives which are intended to ensure interdisciplinary treatment in accordance with the guidelines. One example is the Comprehensive Cancer Center (CCC) Lower Saxony, an association of the Cancer Center of Hannover Medical School, the Cancer Center of the University of Göttingen and other (partly outreach) partners in the region with the aim of facilitating cross-institutional networking and multidisciplinary patient care [2]. At the same time, this platform supports networking in the area of research.

Thus, radiological imaging plays a central role at all stages of oncological care (from prevention and initial diagnosis to followup care). A high quality standard is therefore necessary to ensure adequate patient care. Existing guidelines represent decisionmaking aids for special medical issues [3, 4]. However, on the one hand, it is problematic that such guidelines do not exist for all cancers and on the other, that these guidelines deal with the identical radiological technique in very different ways. This is often treated only superficially without going into detail about requirements (e. g. contrast agent phases and sequences) or quality features of imaging. Likewise, the mere existence of a guideline does not automatically mean that the relevant recommendations will be implemented. As shown in a recent survey conducted by the Gastrointestinal and Abdominal Diagnostics Working Group of the German Radiological Society, the indications for abdominal radiological imaging are largely followed according to the guidelines; nevertheless, there is a substantial heterogeneity in German-speaking countries regarding the examination protocols used [5]. This is certainly also due to the lack of precise recom- mendations for the imaging of individual tumor entities and thus the lack of "radiological guidelines".

Such heterogeneity of examination protocols often means that CT and MRI examinations in particular must be repeated due to limited comparability or poor quality. This primarily concerns examinations of patients who have received their imaging in clinics or practices that follow different standards than the clinic or specialized centers where the patients are presented and receive further treatment [6]. Apart from additional organizational overhead, repeat or supplementary examinations unnecessarily burden our health system [7]. Furthermore, they result in delayed therapy and represent a considerable psychological burden for the patients concerned, who consequently question medical competence [8-10]. Added to this is unnecessary additional radiation exposure in the case of supplementary CT.

In summary, an increasing homogenization of protocols should be sought, especially in the context of establishment of oncological centers, to avoid duplication of examinations, improve overall patient care and enable reliable treatment across institutions and funding agencies. In addition, such agreed standards could also be a quality indicator and serve as a basis for guidelines. The aim of our study was therefore to establish a cross-institutional standardization of CT and MRI protocols for liver and pancreas imaging in an oncology center in a pilot project and to verify compliance with the protocols.

\section{Materials and Methods}

This oncological center study with two participating institutes was approved by the local ethics committees of the participating hospitals. This prospective observational study, evaluated radiological images in the period from June 2019 to August 2019 at Hannover Medical School, Institute 1 and University Medical Center Göttingen Institute 2. Included were CT and MRI examinations, carried out with respect to the issue "Primarily/known liver or pancreatic tumor" in patients $\geq 18$ years old. In addition, extramu- 
- Table 1 Defined protocols for CT examinations of the liver and pancreas. Presented are minimum standard requirements.

\begin{tabular}{|l|l|l|}
\hline & liver & pancreas \\
\hline sequence & $\begin{array}{l}\text { - late arterial } \\
\text { - portal venous } \\
\text { - late venous }(120-180 \sec \text { p. i.) }\end{array}$ & $\begin{array}{l}\text { - late arterial } \\
\text { " portal venous }\end{array}$ \\
\hline slice thickness & $1-1.5 \mathrm{~mm}$ & $1-1.5 \mathrm{~mm}$ \\
\hline p. i. = post-injection. & \\
\hline
\end{tabular}

rally-produced images which were locally scanned into the PACS (Picture Archiving and Communication System) were included and demonstrated during local interdisciplinary tumor conferences with corresponding issues.

\section{Preparation}

Standard protocols for CT and MRI imaging of the liver and pancreas were defined following preparatory discussions among the experts involved at both sites. Minimum requirements were specified regarding the contrast agent phases and layer thickness to be acquired in $\mathrm{CT}$, as well as the sequences to be acquired in MRI ( $\vee$ Table 1,2 ). With a transition period of 1 month, the defined protocols were implemented in clinical routine at both sites.

\section{Evaluation}

Center-internal examinations were filtered out by a corresponding search in the PACS (both locations using Centricity ${ }^{\mathrm{TM}}$ PACS, GE Healthcare, Chicago). Extramural CT and MRI imaging with an appropriate clinical issue was included ad hoc in the tumor conference preparation by a medical specialist. The subsequent evaluation of all examinations was carried out in consensus by a medical student and a specialist in radiology on site. Contrast phases, sequences and respective layer thickness were evaluated for both the internal and external examinations. Examination quality was evaluated on a scale of 1-3 ( 1 = diagnostic value; 2 = limited diagnostic value; 3 = no diagnostic value). In the case of external examinations, the presence of an associated written report was also recorded.

\section{Statistical Evaluation}

Compliance with the minimum requirements of the defined protocols was evaluated using descriptive statistics. Differences between the participating institutes, modalities and organ regions examined were recorded with Fisher's exact test, whereby a p-value below 0.05 was considered significant.

\section{Results}

In total, 480 data sets (397 internal, 83 external) were included in the evaluation ( $\triangleright$ Fig. 1, $\triangleright$ Table 3 ). Institute 1 had a larger proportion of liver examinations ( $84.4 \%)$, Institute 2 had a slightly higher proportion of pancreatic examinations (52.8\%). The external examinations were mainly CTs and MRIs of the liver $(69 \% ; n=57)$.
- Table 2 Defined protocols for CT examinations of the liver and pancreas. Presented are minimum standard requirements.

\begin{tabular}{|c|c|c|}
\hline & liver & comments \\
\hline \multirow[t]{12}{*}{$\begin{array}{l}\text { sequence } \\
\text { (plane) }\end{array}$} & T1w Dixon (axial) & $\begin{array}{l}\text { alternative in-/opposed } \\
\text { phase }\end{array}$ \\
\hline & T1w fs native (axial) & \\
\hline & 3D MRCP* & Primarily for CCA \\
\hline & T1w fs late arterial (axial) & \\
\hline & T1w fs portal venous (axial) & \\
\hline & T1w fs late venous (axial) & \\
\hline & T2w fs (axial) & \\
\hline & $\begin{array}{l}\text { T1w fs post-contrast } \\
\text { (coronal) }\end{array}$ & \\
\hline & DWI (axial) & $\begin{array}{l}\text { b-values } 0-100 \text { and } \\
500-1000 \mathrm{~s} / \mathrm{mm}^{2}\end{array}$ \\
\hline & T2w HASTE (coronal) & alternative IR \\
\hline & $\begin{array}{l}\text { T1w fs hepatobiliary } \\
\text { phase (axial) }\end{array}$ & $\begin{array}{l}\text { only when Gd-EOB-DTPA } \\
\text { (Primovist) administered }\end{array}$ \\
\hline & pancreas & comments \\
\hline \multirow[t]{9}{*}{$\begin{array}{l}\text { sequence } \\
\text { (plane) }\end{array}$} & T1w Dixon (axial) & $\begin{array}{l}\text { alternatively in-/opposed } \\
\text { phase }\end{array}$ \\
\hline & T1w fs native (axial) & \\
\hline & 3D MRCP* & primarily for IPMN \\
\hline & T1w fs late arterial (axial) & \\
\hline & T1w fs portal venous (axial) & \\
\hline & T2w (axial) & \\
\hline & $\begin{array}{l}\text { T1w fs post-contrast } \\
\text { (coronal) }\end{array}$ & \\
\hline & DWI (axial) & $\begin{array}{l}\text { b-values } 0-100 \text { and } \\
500-1000 \mathrm{~s} / \mathrm{mm}^{2}\end{array}$ \\
\hline & T2w HASTE (coronal) & alternative IR \\
\hline
\end{tabular}

$\mathrm{fs}_{\mathrm{s}}$ fat saturation; $\mathrm{MRCP}=$ magnetic resonance cholangiopancreatogra phy; DWI = diffusion weighted imaging; HASTE = half Fourier-acquired single shot turbo spin echo; IR = inversion recovery; IPMN = intraductal papillary mucinous neoplasm. The Dixon (alternatively simple in-/ opposed phase) was defined as a minimum requirement in order to be able to detect possible fat content, especially in case of unclear liver lesions.

\section{Center-internal Examinations}

Evaluation included 397 center-internal data sets (279 CT, $118 \mathrm{MRI}$ ). Of these, 21 examinations (5.3\%) offered limited diagnostic value. These were two CT examinations of the liver, $17 \mathrm{MRI}$ examinations of the liver and $2 \mathrm{MRI}$ examinations of the pancreas (e. g. with artifacts or missing sequences). None of the examinations offered no diagnostic value.

All CTs were acquired with a primary slice thickness of 1$1.5 \mathrm{~mm}$. In $90.7 \%$ of the liver and $100 \%$ of the pancreas examinations, all required contrast phases were represented with respect to triphasic (late arterial, portal venous, late venous) or biphasic (late arterial, portal venous) scanning protocols. The late venous phase was absent in 17 liver examinations (9.3\%). 


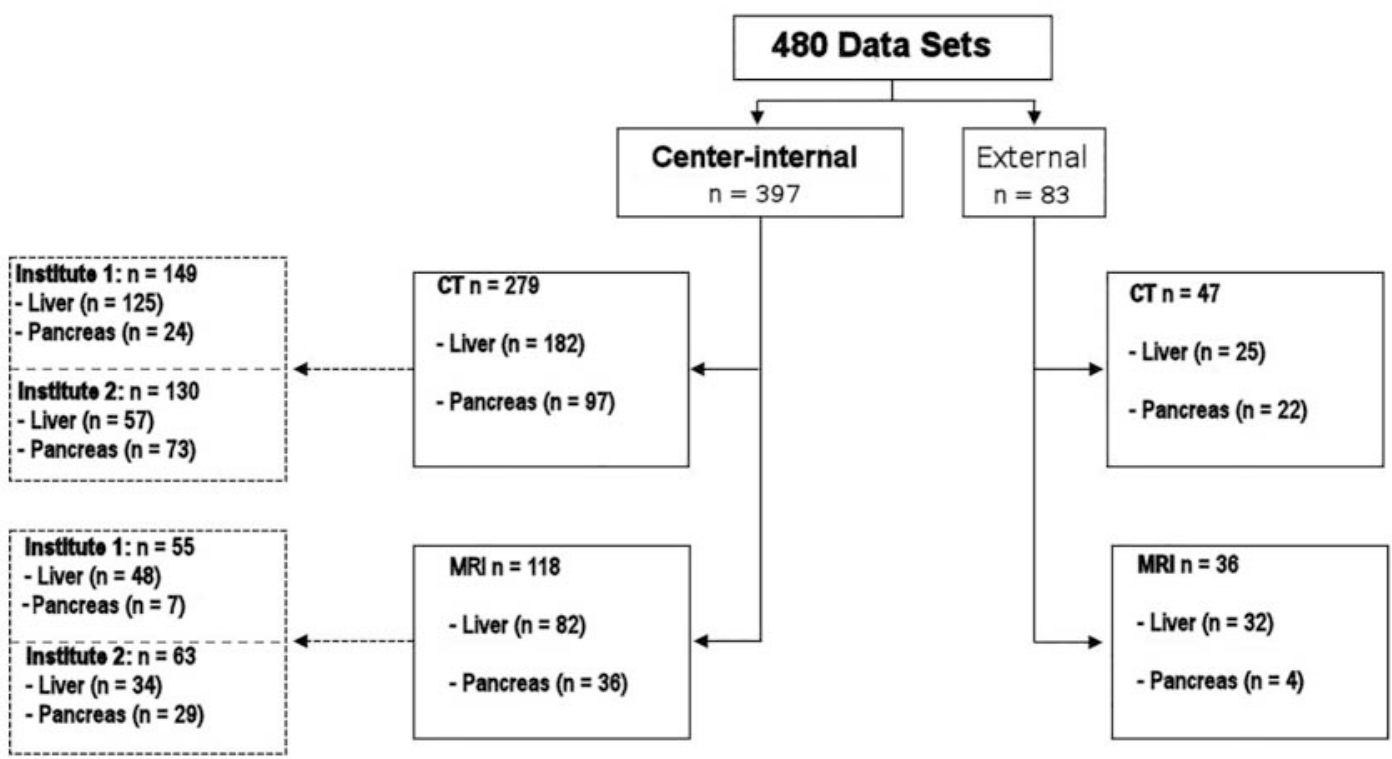

- Fig. 1 The analysis included CT and MRI datasets, which were acquired for evaluation of primary liver or pancreas tumors.

- Table 3 Study CT and MRI data sets with regard to manufacturer and scanner specification.

\begin{tabular}{|c|c|c|c|c|c|c|c|}
\hline & \multicolumn{5}{|c|}{$\mathrm{CT}(\mathrm{n}=326)$} & \multicolumn{2}{|c|}{ MRI $(n=154)$} \\
\hline & 6-slice & 16-slice & 32-slice & 64-slice & $\geq 128$-slice & $1.5 \mathrm{~T}$ & $3.0 \mathrm{~T}$ \\
\hline internal total & 0 & 1 & 1 & 120 & 157 & 75 & 43 \\
\hline . GE & 0 & 1 & 0 & 120 & 0 & 0 & 0 \\
\hline - Philips & 0 & 0 & 0 & 0 & 0 & 1 & 0 \\
\hline - Siemens & 0 & 0 & 1 & 0 & 156 & 74 & 43 \\
\hline - Toshiba & 0 & 0 & 0 & 0 & 1 & 0 & 0 \\
\hline extramural total & 1 & 18 & 6 & 5 & 17 & 33 & 3 \\
\hline - GE & 0 & 3 & 0 & 0 & 0 & 3 & 0 \\
\hline - Hitachi & 0 & 0 & 0 & 0 & 0 & 1 & 0 \\
\hline - Philips & 0 & 1 & 0 & 5 & 0 & 11 & 0 \\
\hline - Siemens & 1 & 6 & 6 & 0 & 13 & 18 & 3 \\
\hline - Toshiba & 0 & 8 & 0 & 0 & 4 & 0 & 0 \\
\hline
\end{tabular}

All required sequences were acquired in $93.9 \%$ of MRI liver examinations. In three patients the coronal T2 HASTE (Half-FourierAcquired-Single-Shot Turbo Spin Echo) sequence was missing; the required MRCP (magnetic resonance cholangiopancreatography) sequence was missing in two patients with cholangiocarcinoma (CCA). The liver-specific contrast agent Gd-EOB-DTPA was used in $95 \%$ of liver MRI examinations; corresponding images were taken in the hepatobiliary phase in all patients. The data sets for pancreatic MRI were complete in $88.9 \%$ of cases. Specifically, a coronal T2 HASTE sequence $(n=2)$, diffusion imaging $(n=1)$ or MRCP were missing in a patient with primarily IPMN (intraductal papillary mucinous neoplasia; $n=1$ ).

At both institutes combined, 371 of 397 (93.5\%) examinations complied with the defined minimum requirements of the examination protocols. There was no essential difference between CT and MRI modalities (93.9\% v. 92.4\%).

\section{Extramural Examinations}

There were 83 evaluated externally-obtained data sets presented during tumor conferences. A written finding was available for 
$79.5 \%$ of the examinations. Of these, $57.1 \%$ were diagnostically valuable, $38.1 \%$ were considered of limited diagnostic value (e. g. with artifacts or missing sequences). Three examinations (3.6\%; two CTs and one MRI) were rated as not diagnostically useful. Specifically, these included a native CT of a patient with known HCC, a pancreatic CT with an excessive layer thickness (more than $3 \mathrm{~mm}$ ) of a patient with primarily IPMN, and a liver MRI with extensive artifacts in all sequences of a patient with primarily HCC.

All required contrast phases were present in only $24 \%$ of the CT scans of the liver (6/25); most frequently acquisition of the late venous phase was omitted (not present in $64 \%$ ). On the other hand, $86.4 \%$ of pancreatic CTs showed all corresponding contrast phases. Overall, the CTs were acquired with thicknesses of up to $5 \mathrm{~mm}$, only $21.3 \%$ (10 of 47) had a layer thickness of 1 to $1.5 \mathrm{~mm}$.

MRI examinations of the liver contained all required sequences in $40.6 \%$ of cases; only one sequence was missing in $28.1 \%$, two sequences in $18.8 \%$, and three or more sequences in $12.5 \%$ of examinations. Most frequently, acquisition of a T1w Dixon sequence/alternatively in- and opposed-phase imaging (in 21.9\%) or coronal T1 after contrast administration (in 18.8\%) was omitted. The liver-specific contrast agent Gd-EOB-DTPA was used in ten MRI examinations; corresponding images were taken in the hepatobiliary phase $90 \%$ of cases. Of the four external pancreatic MRI examinations, the MRCP sequence was absent for one patient with primarily IPMN; in another with primarily pancreatic cancer diffusion imaging was missing.

In short, $48.2 \%$ of the external examinations fulfilled the minimum required contrast phases or sequences. For CT examinations, this value was somewhat higher compared to MRI (53.2\% versus $41.7 \%$ ). If the minimum standard is extended by the criteria maximum slice thickness in CT and the presence of a corresponding written finding, these requirements were fully met by only $20.5 \%$ of the external examinations presented in tumor conferences.

\section{Comparison of center-internal and external Examinations}

In direct comparison, significant differences in protocol adherence were found between center-internal and external examinations ( $p<0.0001)$, overall, modality-related $(C T$ and MRI), but also organ-related (liver and pancreas) ( $\triangleright$ Fig. 2 ). With respect to center-internal examinations, there was no significant difference between the data sets originating from Institute 1 or Institute 2 $(p=0.0615)$. However, compliance with the protocols was significantly better for pancreatic CT than for CT examinations of the liver $(p=0.0009)$. The same applies to CT examinations of the pancreas compared to MRI examinations ( $p=0.00012)$. $>$ Table 4 provides a detailed overview of the data sets including differentiated presentation with regard to origin, modality and organ region.

\section{Discussion}

This pilot study demonstrated the possibility of establishment of cross-institutional standardized examination protocols for CT and MRI imaging of primary liver and pancreatic tumors in one tumor

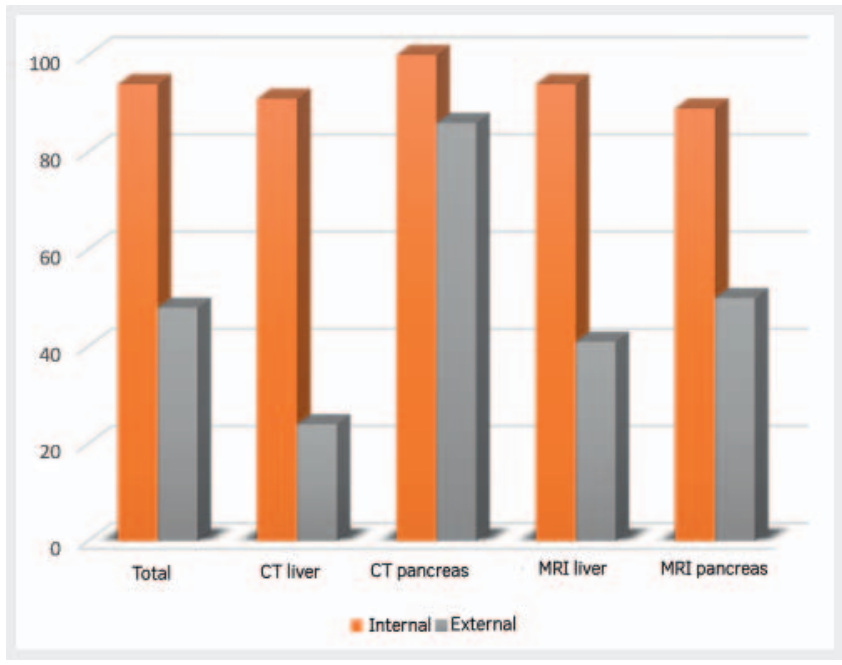

- Fig. 2 Protocol compliance (in \%) dependent on data set origin (in-house or extramural), modality (CT or MRI) and indication (liver or pancreas).

center with a high protocol compliance rate (over $90 \%$ ). In this respect, no significant difference could be shown between the participating institutions. The protocols were followed in $100 \%$ of pancreatic CT examinations. Less than a quarter of the cases of extramural examinations presented in tumor conferences, however, fulfilled the minimum requirements (contrast phases, sequences, maximum layer thickness in the $\mathrm{CT}$ and available written findings). This is not surprising as the protocols were not stipulated with the external clinics and practices. These values were collected to estimate the effects that can be expected from quality assurance measures in a tumor center if the outreach partners are actively involved. Nevertheless, some of the differences were significant, and the diagnostic quality of the external examinations had to be questioned.

Primarily due to its lower complexity, the pancreatic CT protocol was the most reliably established. Likewise, the center-internal implementation of the MRI protocols succeeded reliably; the minimum requirements were regularly met. Minor deviations were mainly due to the absence of an MRCP sequence (for the corresponding indication) or HASTE sequence. It is striking that the late venous phase of the liver $\mathrm{CT}$, which is crucial for the diagnosis of HCC and also for differentiation from CCA, was not acquired externally in $36 \%$ of examinations. However, these results are more positive than those of the survey conducted four years ago by the German Radiological Society, in which only $10 \%$ and $34 \%$ of the participants, respectively, stated that they had a late venous phase recorded for HCC and CCA [5]. Considering that the HCC guideline recommends a 3-phase contrast-enhanced sectional imaging technique (late arterial, portal venous and late venous) [3], these results are nevertheless surprising, but also reflect the heterogeneity of the investigation protocols used in German-speaking countries mentioned earlier in this paper and any underlying uncertainties regarding an adequate investigation technique. 
- Table 4 Protocol adherence of in-house and extramural examinations with respect to required contrast phases and sequences during CT and MRI. Protocol compliance for in-house examinations was $93.5 \%$, for external studies $48.2 \%$ met minimum requirements. The figures correspond to the absolute number of data sets in each category.

\begin{tabular}{|c|c|c|c|c|c|}
\hline & \multicolumn{2}{|l|}{ CT } & \multicolumn{2}{|l|}{ MRI } & \multirow[t]{2}{*}{ total } \\
\hline & liver & pancreas & liver & pancreas & \\
\hline \multirow[t]{2}{*}{ internal only institute 1} & $122 / 125$ (97.6\%) & $24 / 24(100 \%)$ & $43 / 48(89.6 \%)$ & $7 / 7(100 \%)$ & \multirow[t]{2}{*}{ 196/204 (96.1\%) } \\
\hline & \multicolumn{2}{|l|}{ 146/149 (97.99\%) } & \multicolumn{2}{|l|}{$50 / 55$ (90.9\%) } & \\
\hline \multirow[t]{2}{*}{ internal only institute 2} & 43/57 (75.4\%) & 73/73 (100\%) & $34 / 34(100 \%)$ & 25/29 (82.8\%) & \multirow[t]{2}{*}{ 175/193 (90.67\%) } \\
\hline & \multicolumn{2}{|l|}{$116 / 130(89.2 \%)$} & \multicolumn{2}{|l|}{ 59/63 (93.7\%) } & \\
\hline \multirow{2}{*}{$\begin{array}{l}\text { center-internal } \\
\text { (institutes } 1+2 \text { ) }\end{array}$} & 165/182 (90.6\%) & 97/97 (100\%) & 77/82 (93.9\%) & $32 / 36(88.89 \%)$ & \multirow[t]{2}{*}{ 371/397 (93.5\%) } \\
\hline & \multicolumn{2}{|l|}{$262 / 279(93.9 \%)$} & \multicolumn{2}{|l|}{ 109/118 (92.4\%) } & \\
\hline \multirow[t]{2}{*}{ external } & $6 / 25(24 \%)$ & 19/22 (86.3\%) & $13 / 32(40.6 \%)$ & $2 / 4(50 \%)$ & \multirow[t]{2}{*}{ 40/83 (48.2\%) } \\
\hline & \multicolumn{2}{|l|}{ 25/47 (53.2\%) } & \multicolumn{2}{|l|}{$15 / 36(41.7 \%)$} & \\
\hline \multirow{2}{*}{$\begin{array}{l}\text { total center-internal } \\
\text { and external }\end{array}$} & 171/207 (82.6\%) & 116/119 (97.5\%) & 90/114 (78.95\%) & $34 / 40(85 \%)$ & \multirow[t]{2}{*}{$411 / 480(85.6 \%)$} \\
\hline & \multicolumn{2}{|l|}{$287 / 326$ (88.03\%) } & \multicolumn{2}{|l|}{ 124/154 (80.52\%) } & \\
\hline
\end{tabular}

Increasing demands in the care of oncological patients are accompanied by high demands on radiological imaging. Certain examination standards should be developed since practically every tumor patient is and should be presented at least one interdisciplinary tumor conference, and that the course of the disease is regularly discussed there [11-13], and also since concomitant imaging has varying sources. The establishment of minimum requirements for certain types of tumors and issues could help to prevent double or repeat examinations, e. g. due to poor quality. This would both save costs and avoid unnecessary delays in patient care. In an environment such as the Comprehensive Cancer Center Lower Saxony, which includes two university hospitals and many outreach partners in the area, this can contribute to an improvement in patient care. A certain homogenization of protocols in abdominal imaging is also in the interest of the Gastrointestinal and Abdominal Diagnostics Working Group of the German Radiological Society [5, 14]. Another added value of standardized, highquality imaging is the generation of more reliable data for studies with the possibility of developing more precise therapies. At this juncture, it should also be noted that a written report is an integral part of every examination [15]; however, it is not uncommon for this to be absent, particularly during presentations in the tumor board [16], although it is of decisive importance and also makes the preparation of the conference considerably easier while enhancing the quality of the content. There are also clear recommendations from a legal perspective. Even if one should not rely on the external findings when presenting extramural images, written primary findings are part of the examination and should be available when preparing a second radiological opinion. This is the only way to ensure that a complex medical situation, as is of- ten the case in tumor conferences, can be adequately assessed radiologically [17].

Our study has some limitations. The number of newly implemented and reviewed protocols in this pilot project is limited to two organ regions and two modalities. Moreover, only the primary partners in the CCC-N, both university hospitals, had agreed on the study. As expected, extramural examinations therefore met the defined minimum requirements significantly less frequently, as the examination protocols were not stipulated. Furthermore, in individual cases it was not always possible to check whether the issue was already known at the time of the examination, whether a patient had discontinued the examination or whether the administration of contrast medium was not possible for various reasons. Based on the results of this pilot study, we will now involve further clinics and practices (outreach partner in the CCC-N) to further investigate the effects of standardization, but also the suitability of imaging as a quality parameter of a CCC.

In summary, in this pilot project on CT and MRI in primary liver and pancreatic tumors we were able to show that a standardization of examination protocols in a tumor center leads to a good adherence to defined parameters. These positive results are encouraging and should be reason enough to strive for a nationwide standardization of protocols in order to improve the care of oncological patients at all disease stages.

\section{Conflict of Interest}

The authors declare that they have no conflict of interest. 


\section{References}

[1] Zentrum für Krebsregisterdaten. https://www.krebsdaten.de/Krebs/DE/ Datenbankabfrage/datenbankabfrage_stufe1_node.html; Zugriff am 03.03.2020

[2] Comprehensive Cancer Center Niedersachsen. https://www.mhh.de/ claudia-von-schilling-zentrum-ccc-hannover; Zugriff am 03.03.2020

[3] Leitlinienprogramm Onkologie (Deutsche Krebsgesellschaft, Deutsche Krebshilfe, AWMF): Diagnostik und Therapie des hepatozellulären Karzinoms, Langversion 1.0, AWMF Registrierungsnummer: 032-053OL. https://leitlinienprogramm-onkologie.de/Leitlinien.7.0html

[4] Leitlinienprogramm Onkologie (Deutsche Krebsgesellschaft, Deutsche Krebshilfe, AWMF): S3-Leitlinie Exokrines Pankreaskarzinom, Kurzversion 1.0, AWMF Registrierungsnummer: 032-010OL. https://leitlinienprogramm-onkologie.de/Leitlinien.7.0html

[5] Schreyer AG, Wessling J, Grenacher L. Versorgungsrealität vs. leitliniengerechte Bildgebung in der Abdominalradiologie im deutschsprachigen Raum: Ergebnisse einer Online-Umfrage. Fortschr Röntgenstr 2016; 188 : 268-279

[6] Jones AC, Woldemikael D, Fisher T et al. Repeated computed tomographic scans in transferred trauma patients: Indications, costs, and radiation exposure. J Trauma Acute Care Surg 2012; 73: 1564-1569

[7] Tierney WM, Fendrick AM, Hirth RA et al. The clinical and economic impact of alternative staging strategies for adenocarcinoma of the pancreas. Am J Gastroenterol 2000; 95: 1708-1713

[8] Bauer MR, Bright EE, MacDonald J] et al. Quality of Life in Patients With Pancreatic Cancer and Their Caregivers: A Systematic Review. Pancreas 2018; 47: 368-375
[9] Chiu C], Hsu YC, Tseng SP. Psychological prognosis after newly diagnosed chronic conditions: socio-demographic and clinical correlates. Int Psychoger 2017; 29: 281-292

[10] Dengso KE, Andersen EW, Thomsen T et al. Increased psychological symptom burden in patients with pancreatic cancer: A population-based cohort study. Pancreatology 2020 Jan 8 (epub ahead of print)

[11] Brauer DG, Strand MS, Sanford DE et al. Utility of a multidisciplinary tumor board in the management of pancreatic and upper gastrointestinal diseases: an observational study. HPB (Ocford) 2017; 19: 133-139

[12] Bumm R, Siess M, Lange M et al. Notwendige Voraussetzungen für die Funktion eines onkologischen Kompetenzzentrums. Dtsch Med Wochensch 2002; 127: 907-912

[13] Lamb BW, Green JS, Benn J et al. Improving decision making in multidisciplinary tumor boards: prospective longitudinal evaluation of a multicomponent intervention for 1421 patients. J Am Coll Sur 2013; 217: 412-420

[14] Hacklander T. Standardisierung des radiologischen Befundberichts Norm DIN 6827-5. Fortschr Röntgenstr 2004; 176: 1481-1484

[15] Grenacher L, Juchems MS, Holzapfel K et al. Aktuelle Schwerpunkte und Literatur der Abdominalradiologie im deutschsprachigen Raum - Teil 2: Parenchymatöse Oberbauchorgane. Fortschr Röntgenstr 2016; 188: 245-252

[16] Schreyer AG, Dendl LM, Antoch G et al. Interdisciplinary tumor boards in the radiological routine: Current situation based on an online survey in Germany. Radiologe 2020 Apr 29 (epub ahead of print)

[17] Schreyer AG, Rosenberg B, Steinhäuser RT. Externally acquired radiological image data and reporting for the clinical routine, conference and boards - Legal aspects of the second opinion in Germany. Fortschr Röntgenstr 2018; 190: 610-615 